\title{
ELEGIES FOR THE PROPHET'S FAMILY BY \\ CONTEMPORARY LEBANESE CHRISTIAN POETS
}

\author{
Khalid Ahmad SINDAWI ${ }^{1}$
}

\section{Istanbul / Türkiye \\ p. $670-685$}

Received: $27 / 11 / 2021$

Accepted: $10 / 12 / 2021$

Published: 01/01/2022

This article has been scanned I iThenticat No plagiarism detected

\begin{abstract}
:
The study discusses elegiac poetry on the Prophet's family composed by Lebanese poets belonging to the Christian community there. We chose a selection of writings by four contemporary Christian poets: Joseph al-Hāshim, Paul Salāma, Raymond Qasīs and Joseph al-Harb. The study opens with a discussion of the meaning of elegies as a human, social and individual poetic object, that has been cultivated by poets since pre-Islamic times. Next, the study discusses the reason why the Prophet's family has been the subject of so many elegies, namely the important position this family occupied among poets. Subsequently we discuss why Christian poets in Lebanon have composed numerous elegies for members of the Prophet's family, especially 'Alī b. Abī TTâlib and his son al-Ḥusayn b. 'Alì, namely the fact that elegies constitute a unique human phenomenon that is in keeping with divine teachings, especially concerning the Prophet's family. The study uses both descriptive and analytic methods.
\end{abstract}

Key words: The Prophet's Family, Elegy, Al-Husayn B. 'alī, 'alì B. Abī Țâlib, Contemporary Arabic Poetry, Christian Poets, Lebanon, Christian Poetry, Shī'ī Poetry.

http://dx.doi.org/10.47832/2717-8293.15.46 


\section{رثاء أهل البيت لدى شعراء النّصارى اللّنبانيّين المعاصرين}

\section{خالد أحمد سِـنداوي 2}

الملخص: يهاف هذا البحث إلى الوقوف عند رثاء أهل البيت لدى شعراء لبنانيّين ينتمون للطّائفة المسيحيّة، وقد اختار

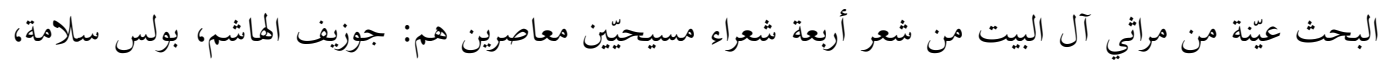

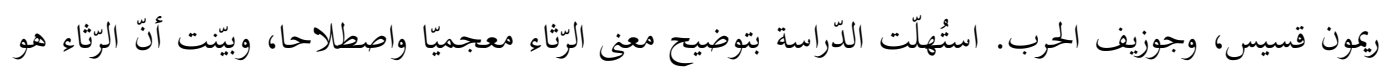

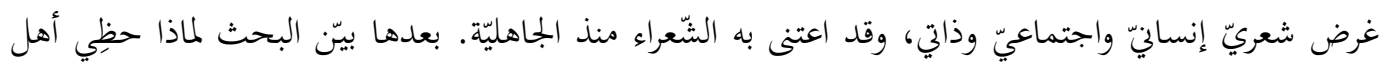

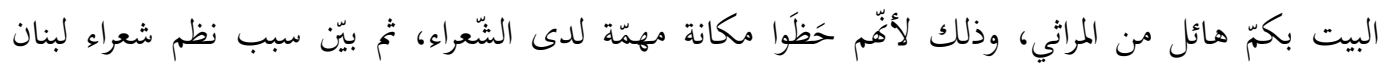
النّصارى مراثٍ عديدة في آل البيت خاصّة في علي بن أبي طالب وابنه الحسين بن علي، وذلئ وذلك لأنّ الرّثاء ظاهرة

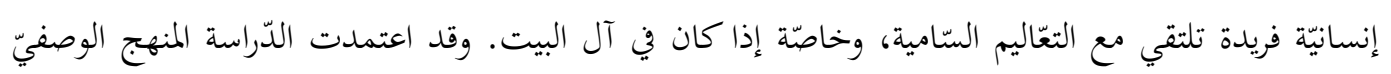

الكلمات المفتاحية: أهل البيت، الرّثاء، الحسن بن عليّ، عليّ بن أبي طالب، الشّعر العربيّ المعاصر، شعراء النّصارى، لبنان، الشّعر المسيحيّ، الشّعر الشّيّيّ.

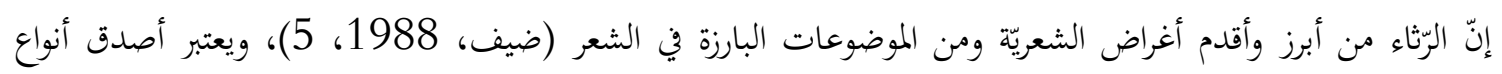

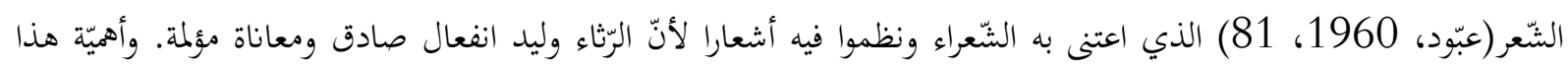

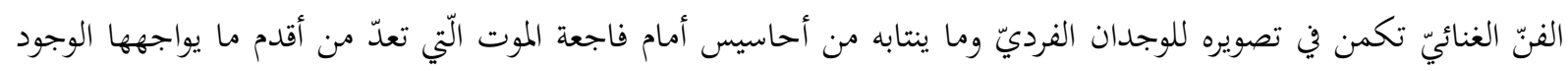

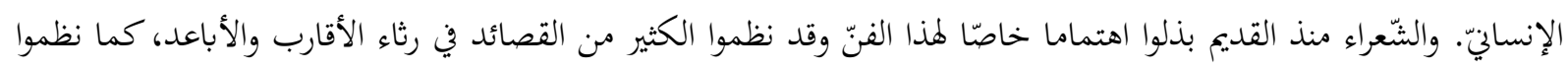

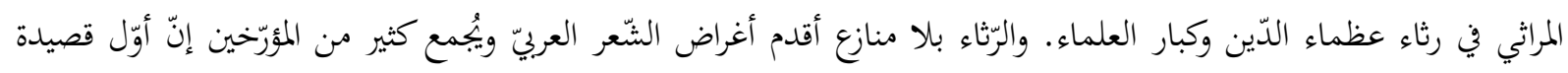

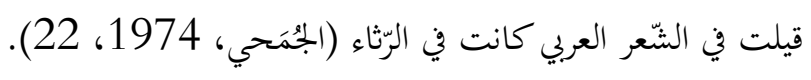

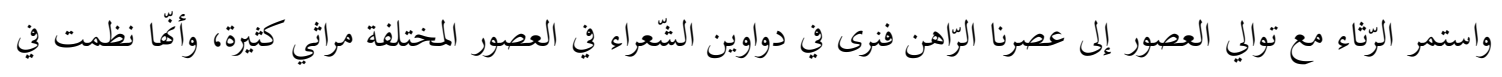

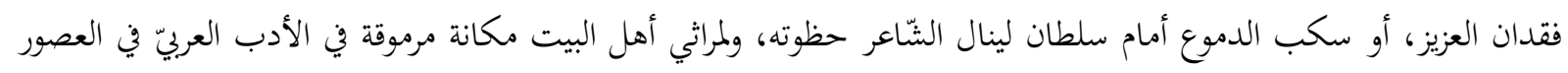

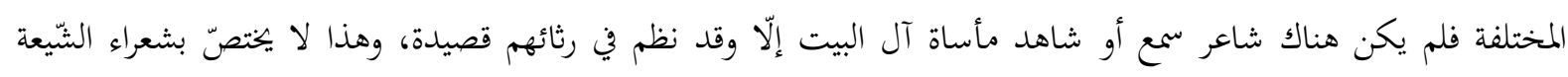

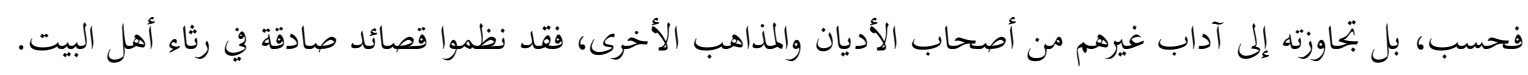

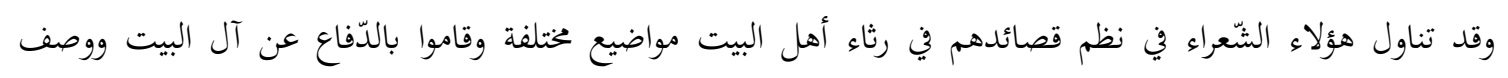
مصائبهم والمحن التي واجهها أهل البيت أثناء حياتم. لم يتّبع الشعراء في نظم مراثي أهل البيت طريقا واحدا ولكن من خلال دراسة هذه المراثي يمكن الإشارة إلى عدّة ميزات

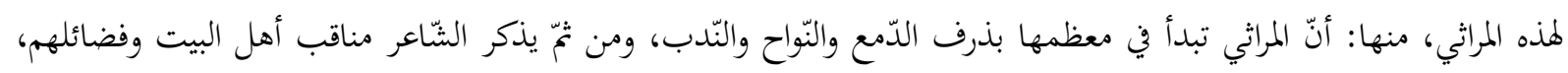


وذكر بعض أحاديث من الرّسول التي تدلّ على الخلافة لعليّ من بعد وفاته، ووصيّته في حبّ آل البيت وذمّ أعداء آل البيت،

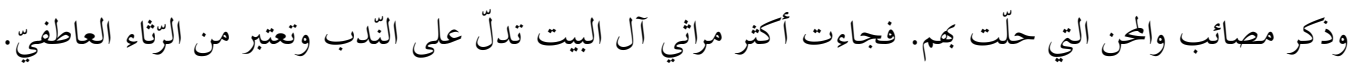

وقد تأثّر الشّعراء أشدّ التأثير بواقعة الطَّنَّ وأحداثها وما أصاب الحسين يوم عاشوراء عام 680م، فنرى المراثي التي

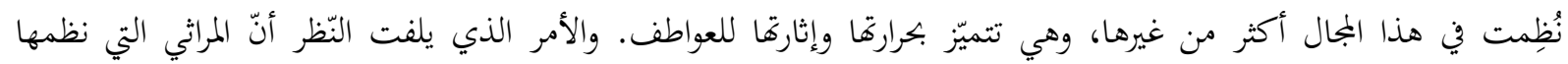

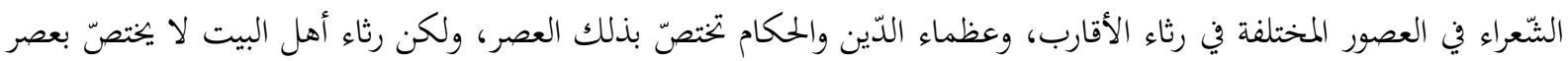
دون العصور، بل قد اهتمّ الشعراء في جميع العصور الأدبيّة برثاء آل البيت وقد صوّر الشعراء عظمة آل البيت ومكاءنتهم في

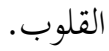
وما زال النظم في رثاء أهل البيت متدفّقا حتّى عصرنا الراهن، فهناك شعراء قد نظموا قصائد في رثاء أهل البيت منهم

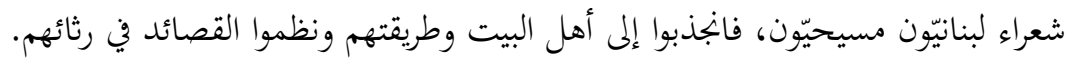
إنّ المدف المتوخّى من هذا المقال هو دراسة مراثي أهل البيت التي نظمها شعراء مسيحيّون من لبنان ونسعى في هذا المجال

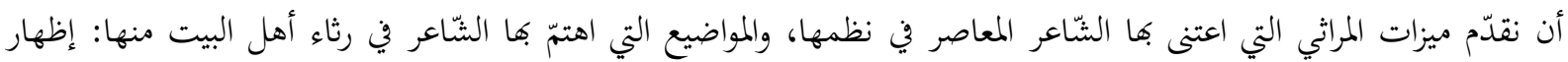
الحزن والألم من مقتل أهل البيت، ذكر فضائل أهل البيت وعظمتهم، وصف المصائب والمحَن الّتي واجهها أهل البيت ودور أهل

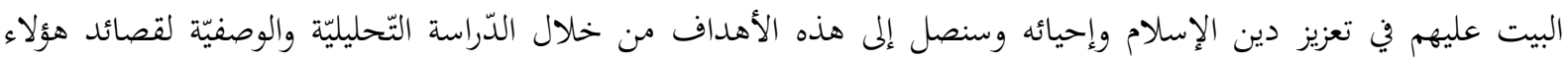

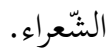

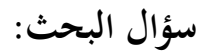
يسعى البحث للإججابة على هذه الأسئلة:

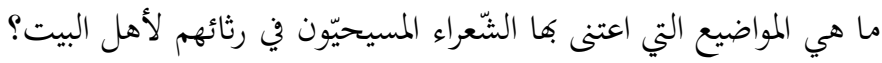

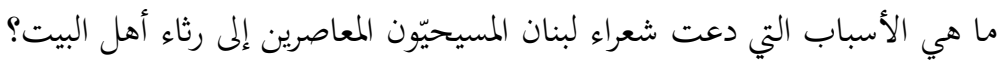
وما هي مميزات مراثي شعراء لبنان المسيحيّون المعاصرين في آل البيت؟

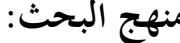

نظرا لطبيعة الدّراسة فقد اعتمد هذا البحث على المنهج الوصفيّ والمنهج التّحليليّ، أي وصف وتحليل مراثي آل البيت التّي اختيرت كعيّات للبحث، ومعالجتها وتحليلها ومقارنتها ببعضها لاستخلاص دلالاتحا والوصول إلى نتائج وتعميمات عن مراثي آل البيت لدى شعراء لبنان المسيحيّين.

الرّثاء في اللّفة والمصطلح

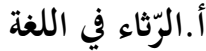

عندما نعود إلى مصادر التّراث في اللّغة العربيّة وهي غنيّة جدّا، نجد ثلاثة أصول لكلمة الرّثاء، حدّدها علماء اللّغة في معاجمهم وهذه الأصول هي:

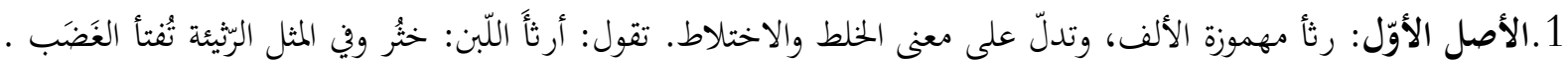

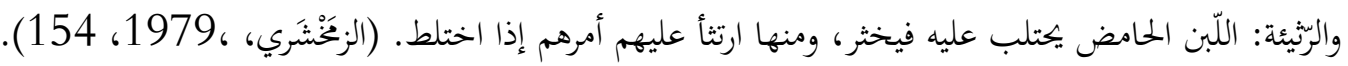


2.أمّا الأصل الثّاني فهو: رثى بالألف الليّنة ومضارعه يرثي و المرثيّة بالفتح وجَع في الرَكبتَين والمفاصل (الجوهري، 1990، 14:

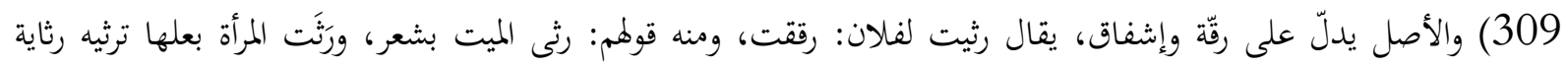

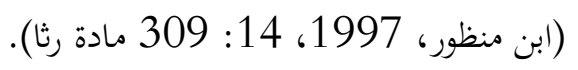

3.أمّا الأصل الثّالث فهو: رثّ بالتّضعيف، وهو أصل واحد يدلّ عل أخلاق وسقوط. يقال ثوب رثّ، ورجل رثّ الهيئة.( ابن

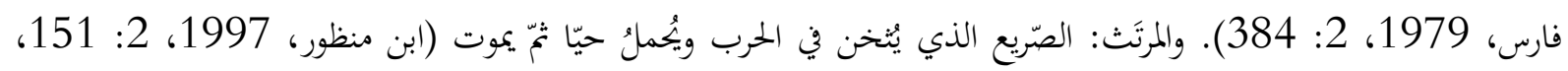
مادّة رثت) .

ب.الرّثاء اصطلاحا

كلمة الرّثاء اصطلاحا تعني: بكاء الميت وذكر مناقبه شعرا أو نثرا. و المرثيّة و الرّثاء: بكاء الميّت وتعداد محاسنه، فيقال:

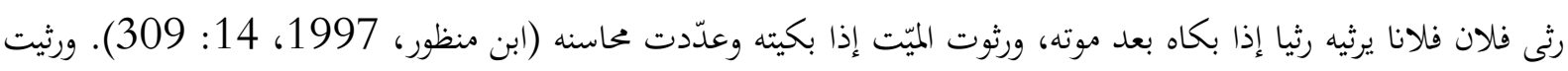

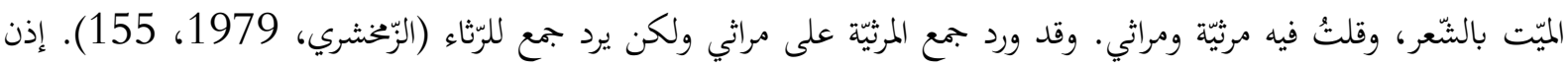

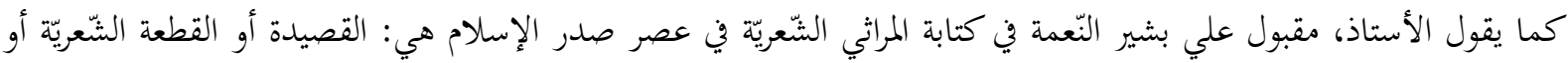

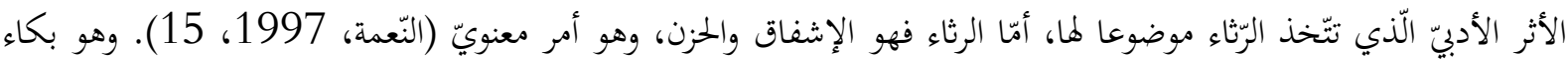

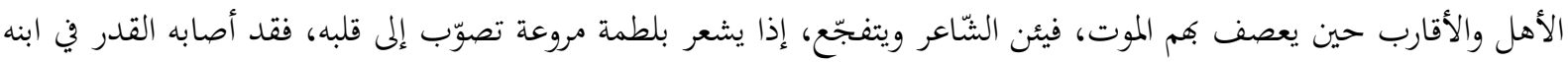

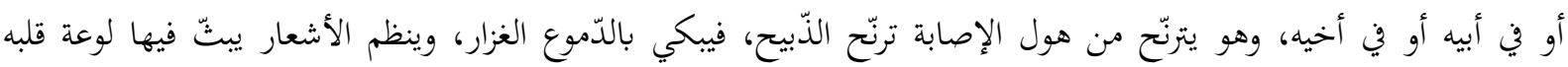

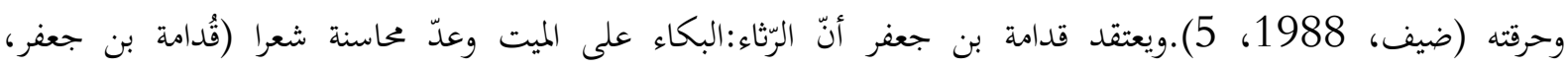

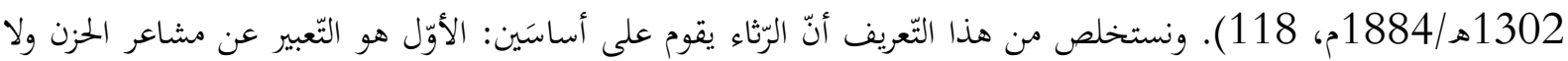
رثاء بدونه، والثاني ذكر محاسن المرثي له وأبجاده.

أمّا البكاء على الميّت والتّعبير عن مشاعر الحزن والأسى أمر ضروريّ إذ لا يستقيم الرّثاء بدونه، وهذه العاطفة هي التي

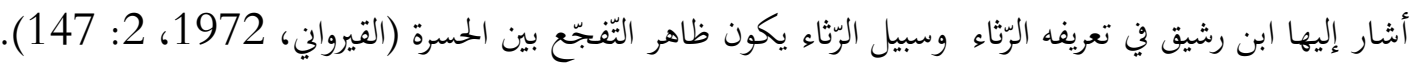
ولقد تداخل المعنى الاصطلاحيّ بالمعنى اللغويّ للرثاء فأصبح المعنى يمثّل مدلولا واحدا عند بعض النّاد. وقد أشارت

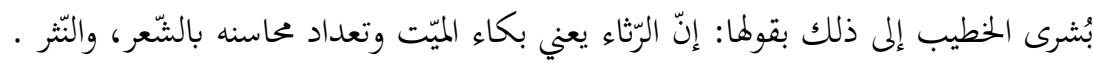
ولكل" أمّة مراثيها، والأمّة العربيّة من الأمم الّتي تحتفظ بتراث ضخم من المراثي، وهي تأخذ عندها ألوانا ثلاثة وهي،

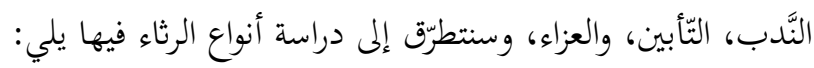
النّدب: هو بكاء الأهل والأقارب حين يعصف بهم الموت، فيئنّ الثّاعر ويتفجّع وينظم الأشعار ليبثّ فيها لوعة قلبه وحرقته. التّأبين: وليس التأبين نواحا ولا نشيجا على هذا النّحو، بل هو أدنى إلى الثنّاء منه إلى الحزن الخالص، إذ يخرّ نجم لامع من سماء

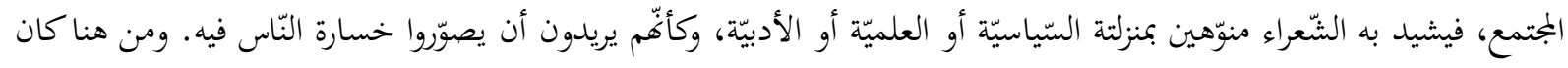

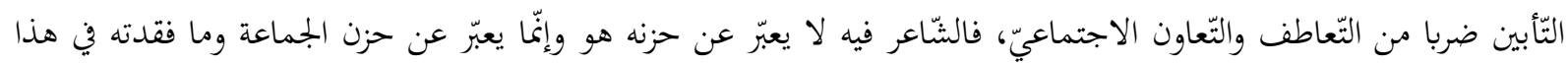

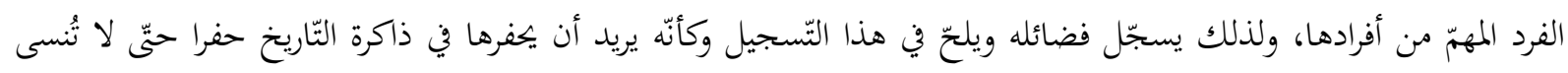

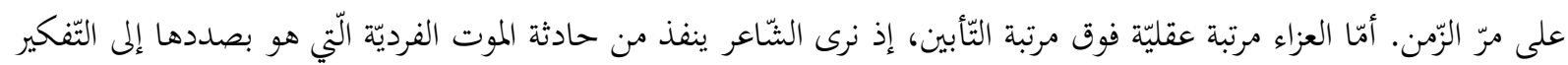

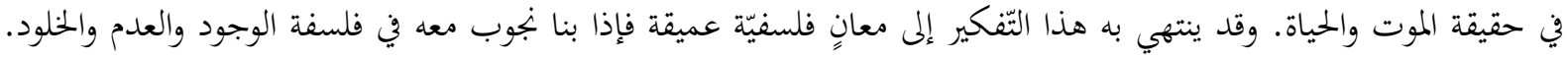

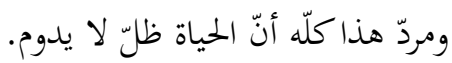


ونشاهد هذه الألوان الثّالثة من الرّثاء في جميع مراثي الشّعراء من عصر الجاهليّ إلى عصرنا الرّاهن سواء أكان رثاء خاصّا

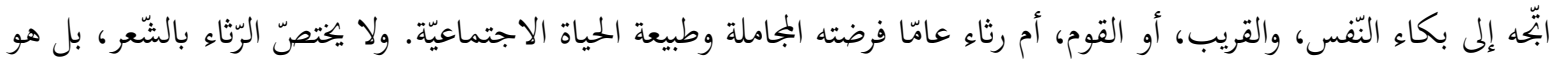
شائع في النّر والشّعر ولكن غلب هذاء الفنّ في الشّعر.

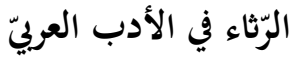

عَرف العرب شعر الرّثاء منذ العصر الجاهليّ لأنّ الرّجال والنّساء جميعا كانوا يندبون الموتى، كما كانوا يقفون على قبورهم

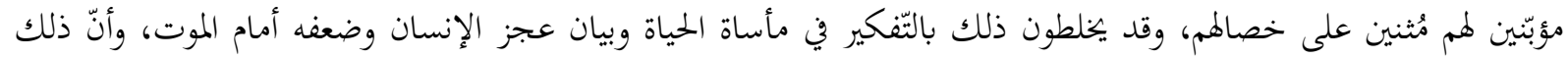
مصير محتوم. - مانم شعر الرّثاء فهو كان في أصله "تعويذات للميّت حتّى يطمئنّ في قبره". ولا بدّ أنّ هذه الصّورة الأوّليّة من الرّثاء خضعت

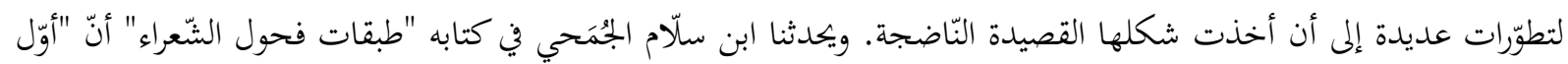

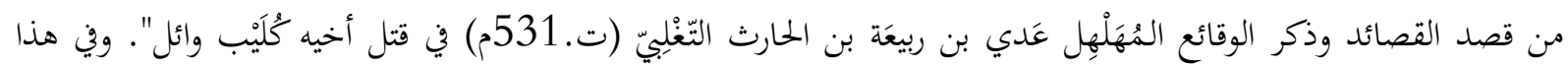
الخبر دلالات هامّة منها: 1. أنّ وقوع الموت كان من أقوى دوافع الشّعراء لنظم الأشعار في الرّثاء. 2. أنّ شعر الرّثاء وليد انفعال صادق ومعاناة مؤلمة. 3. أنّ الإنسان المخزون يحاول أن يخفّف من أحزانه بواسطة الشّعر. وتطوّرت قصائد الرّثاء في العصر الجاهليّ، إذ نرى قد استُخدم في نظمها وسائل فنيّة كثيرة، وقد نوّعوا هذا الفنّ تنويعا

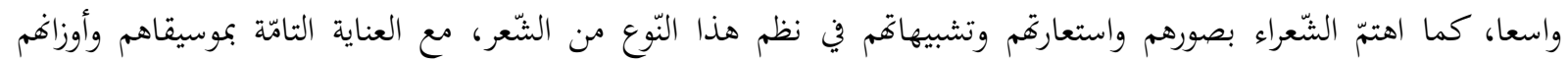

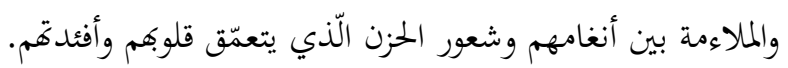
وكان يساهم في هذا الفنّ النّساء الرّجال والنّساء، بل ربّما كان للنّساء حظّ الأوفر من القيام عليه، إذكنّ هنّ اللائي يقمن

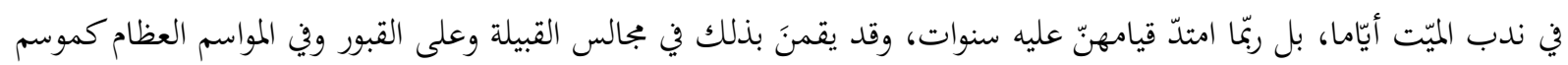
عُكاظ.

ومن الطبّعي أن يتفوّق النّاء على الرّجال في ندب الموتى والنّواح عليهم، لأنّ المرأة أدقّ حِسّا وأرقّ شعورا، وأيضا فإنّ

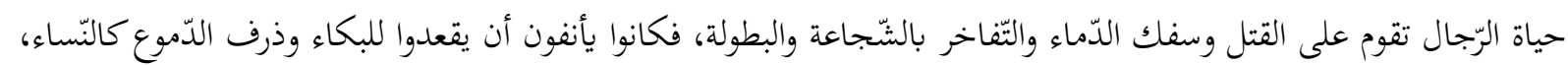
بل لقد ذهبوا يظهرون التّجلّد والصّبر على من يموت منهم.

وهذه الصّور الجاهليّة للرّثاء استمرت في الأدب العربيّ مع عصوره المختلفة، تارة تنمو وتارة تتطوّر، تحت أثير نمو العقل

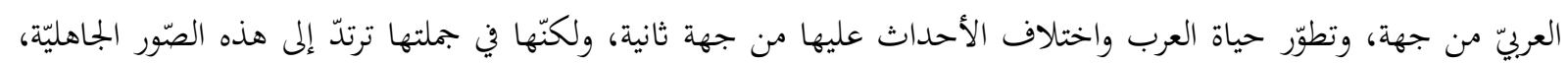
وتشتقّ منها كما يشتقّ الفرع من أصوله.

\section{رثاء أهل البيت لدى شعراء لبنان المسيحيّين}

إنّ دراسة شعر شعراء لبنان المعاصرين، تُبيّن لنا أدب هذا القطر العربيّ قد شاهد تطوّرا ملحوظا في العصور المختلفة، إنّ

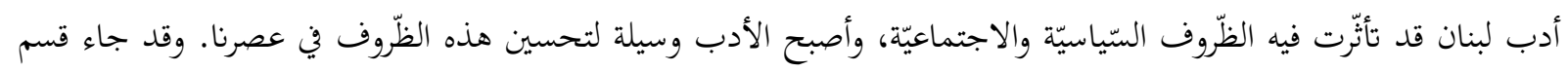

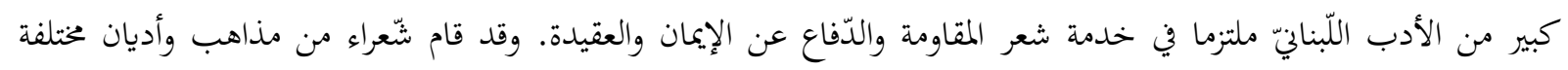


كالمسيحيّة وغيرها قاموا بالدّفاع عن وطنهم وعقيدقم وإيماغم، واتِّذوا عظماء الدّين أسوة لأنفسهم، فجاء شعرهم شعرا ملتزما،

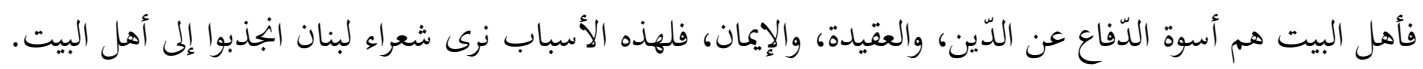
أمّا القصائد التّي نُظمت في رثاء الحسين بن علي، فهي أكثر ظهورا في شعر شعراء لبنان. فقد نظم شعراء لبنان المسيحيّون

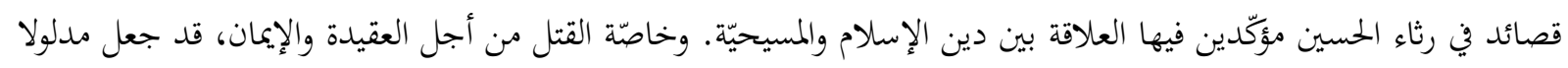

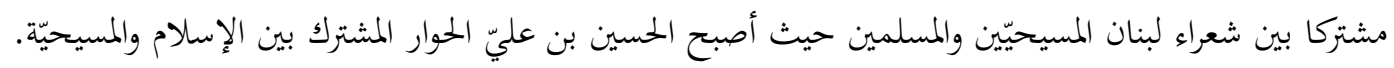
ولم يكتفِ شعراء لبنان المسيحيّون في رثاء الحسين بن عليّ ويوم عاشوراء بوصف الأحداث والمصائب الّتي شهدها آل

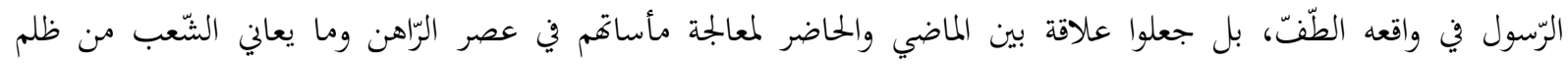

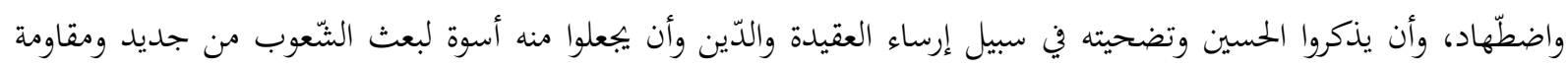
الظّلم والوقوف في وجه الطُّاة. فلهذا يصبح الحسين أسوة المقاومة والاستشهاد في شعر شعراء لبنان المعاصرين. وقداء وقد تطرّق

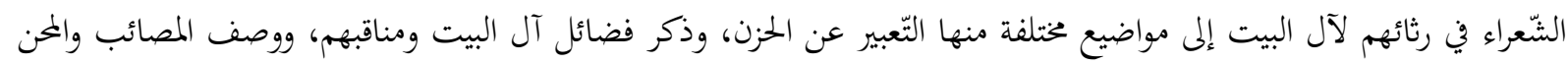

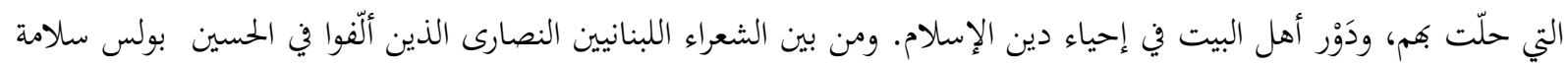

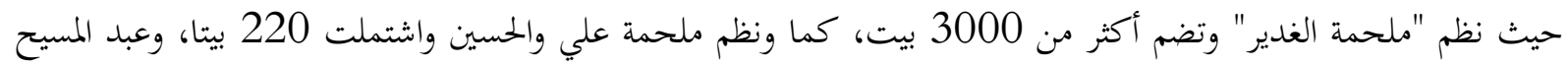

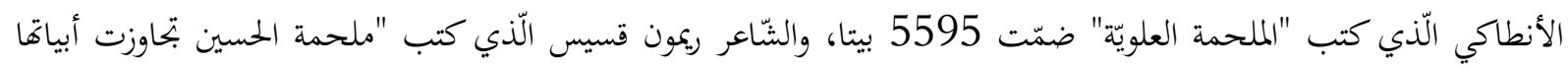

\section{التّعبير عن الحزن في رثاء أهل البيت}

تبدأ قصائد الرّثاء عادة بالبكاء ويصوّر الحزن والالم الذي حلّ به إثر فاجعة فقدان الأحبّة والأصدقاء والأقرباء و....

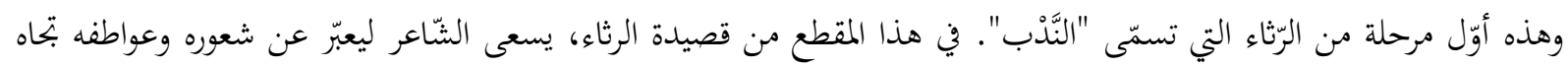

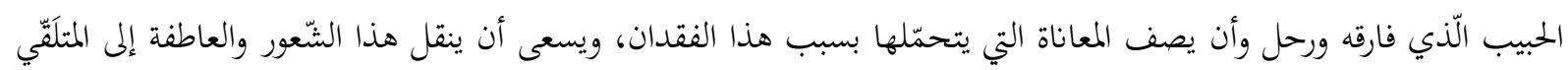

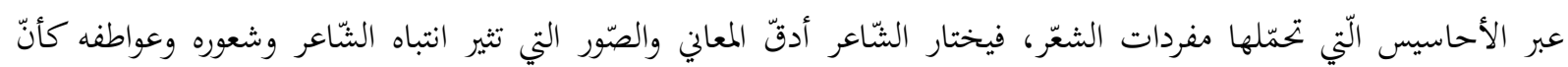
المتلقيّ هو الذي أُصيب بهذا الفقدان المفاجئ.

ولا تُستثنى المراثي التي نُظمت في رثاء أهل البيت إذ نرى هذه المراثي كغيرها تبدأ بالنّدب والتّعبير عن الحزن والأسى في

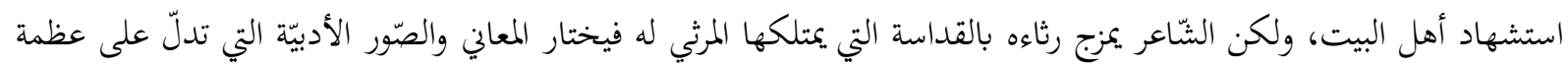

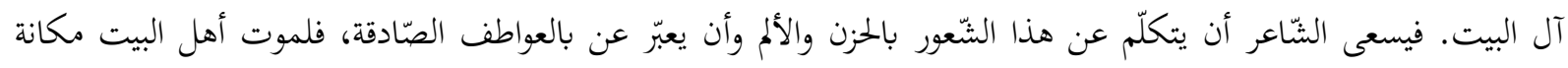

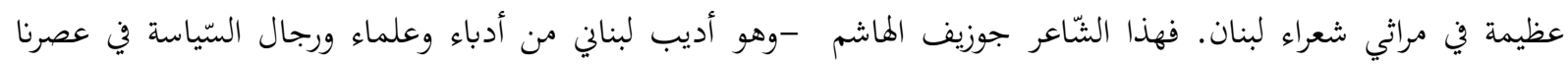

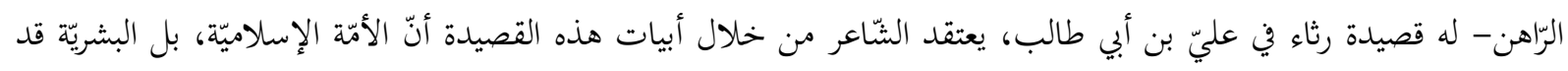

خسرت خسرانا عظيما بمقتل علي بن أبي طالب فيقول:

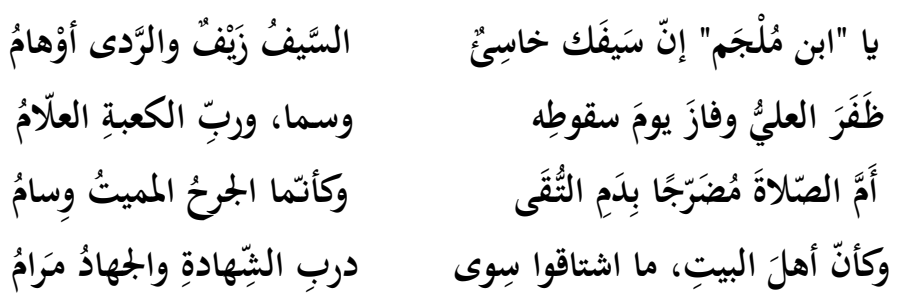

(الهاشم، 1999، 18) 
يشير الشّاعر في هذه الأبيات إلى تلك العبارة التي قالها علي في أثناء صلاة الصّبح عندما ضربه عبد الرحمن ابن مُلْجَم المُرادِيّ (ت. 661م) في رأسه، فقال: "فُزتُ وربّ الكعبةِ" وتشير هذه العبارة إلى غربة عليّ واشتياقه إلى الاستشهاد.

لم يكن مقتل الامام علي حادثة مفجعة فحَسب، بل هو رمز الصّمود وتضحية النّس من أجل العقيدة والإيمان وهو ركز

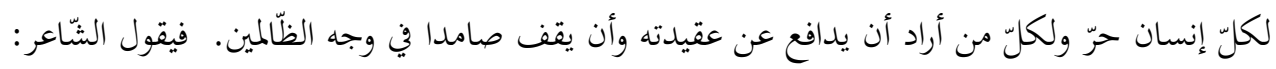

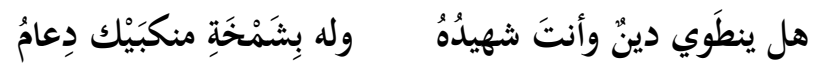

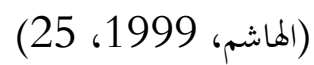

فيعتقد الثّاعر أنّ الدّين الذي قُتِل من أجله عليّ بن أبي طالب سيبقى على مدى الحياة ولن ينمحي من أذهان العالم،

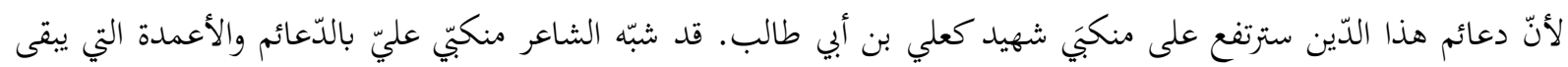
عليها الدّين مستحكِما وبهذا أشار الشّاعر إلى عظمة عليّ ودوره في تحكيم أساس الدّين. وللشّاعر بولس سلامة من شعراء لبنان قصيدة تحت عنوان "ملحمة عيد الغَدير" يتكلّم فيها بعاطفة صادقة عن مقتل

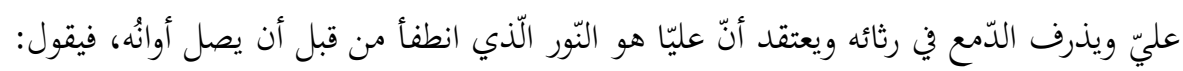
غابَ ضوءُ النّهارِ قبَل انقضائهِ هاتِ يا شعُر أدمُعا لرثائهِ فالأثيرُ الطّهورُ في أجوائسـِ واذكرِ النّسرَ عاليا لمُ يُدنَّس ويسدُّ الفضاءَ رحبِّ فضائهُ يكسف الثّمسَ بالجناح عريضًا من مناط العيّوقِ في إسرائهِ

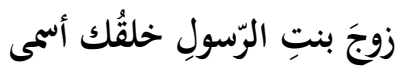
لا يمسٌُ الغبارُ كُنهَ صفاتِهِ شيمةُ النّورِ أن يظلَّ نقيّّا (سلامة، 1423هـ/2002م، 183- 187)

فالشّاعر في هذه الأبيات يتكلّم عن عظمة عليّ ويشبهه بالنَّسر في علو شأنه وشجاعته ويعتقد أنّ مكانته أعلى من

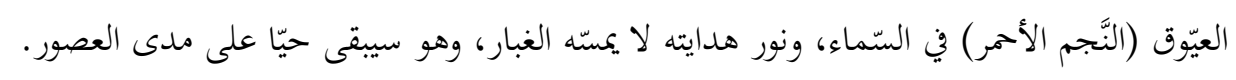
ويواصل الشّاعر ويقول:

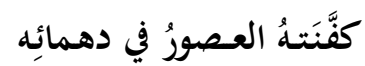
يـا عدوَ السَّماءِ في بغضائِه حين غابَ الإمامُ من فقهائهُ

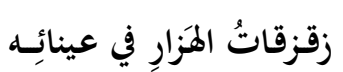

ليتَ يومًا قد جاءَ بابنِ مُراد ايه عبدَ الرّمَمِ نذلَ مُرادِ

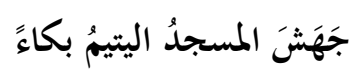

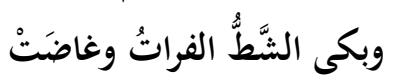

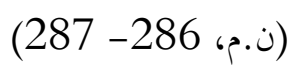

يعتقد الثّاعر أنّ عليّا بمقتله في محراب مسجد الظّهِهر بالكوفة الّذي هو موضع الإيمان وتمام الدّين. وقد جاء الثّاعر هذذه

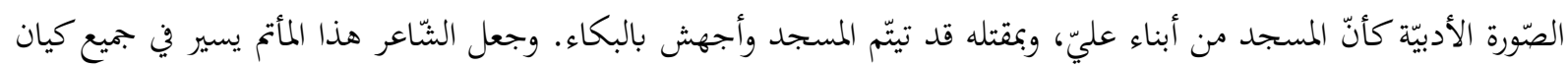
العالم حيث يبكي شطّ غر الفرات، عصافير الهزَار.

ويشير الشّاعر بولس سلامة في المقطع الأخير من قصيدته إلى واقعة الطَّنبّ، ويبيّن كيف تأثّرّ بأحداث كربلاء وأحبّ

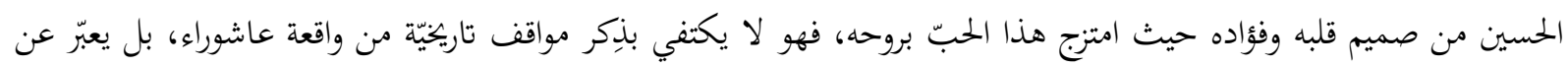

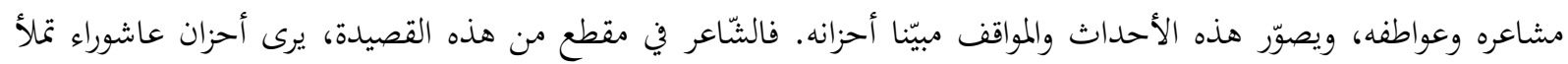

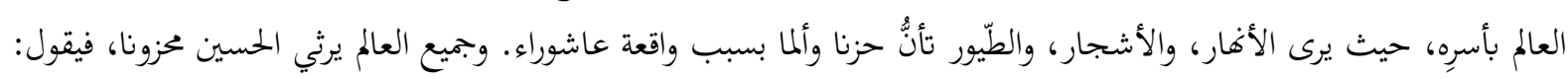




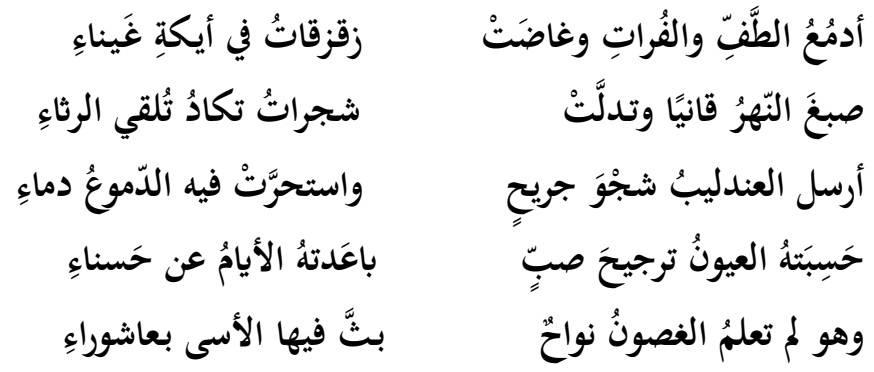

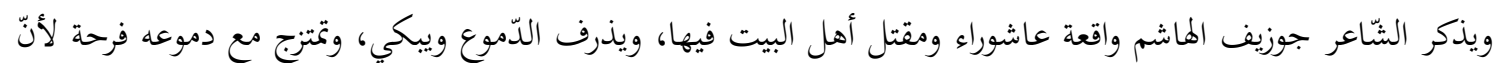

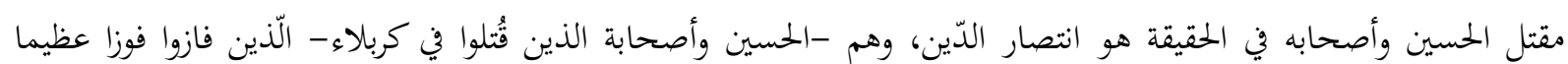
بمقتلهم، وقد خسر أعداء الإسلام وأنّ انتصارهم كان بالظّاهر، فيقول:

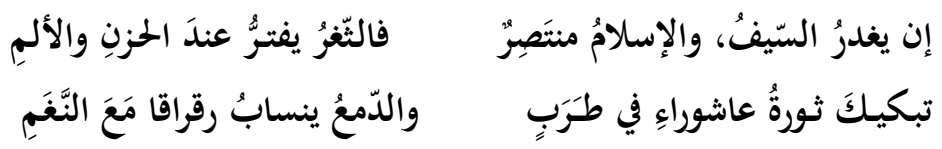

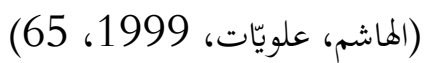

أمّا الثّاعر جوزيف حرب فقد تناول في قصيدة له موسومة بـ "بكائيّة رأس الحسين" رثاء الحسين بن عليّ وأصحابه،

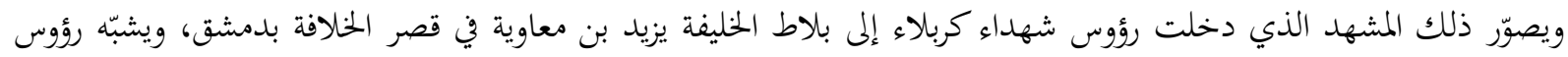

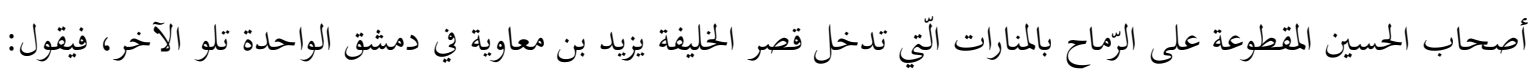

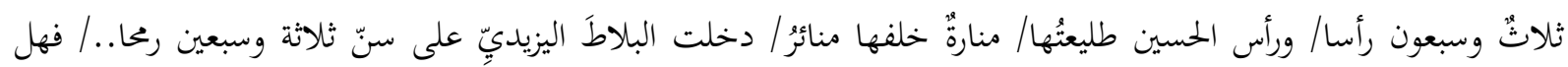

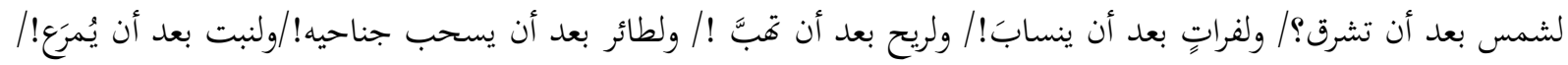

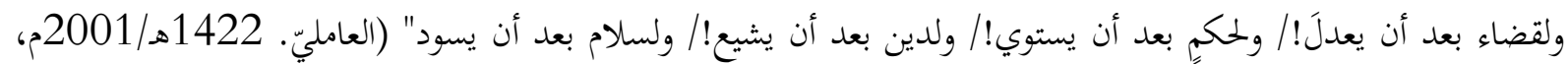
إنّ الثّاعر في هذا النّصّ الشّعريّ يرى أنّ الحزن يسري في جميع العالم بسبب مقتل الحسين، فالشّمس لا تشرق من بعده،

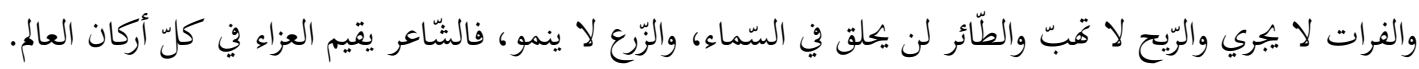

\section{ذِكر فضائل أهل البيت}

إنّ الشّاعر في رثائه يذكر محاسن الميّت، وفضائله وحَسبَبه ونَسَبَه وهذا ما يُسمّى التّأبين، وليس التَّبين نواحا ولا نشيجا،

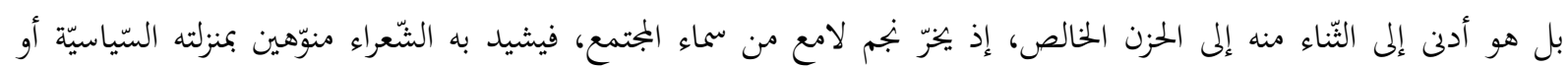

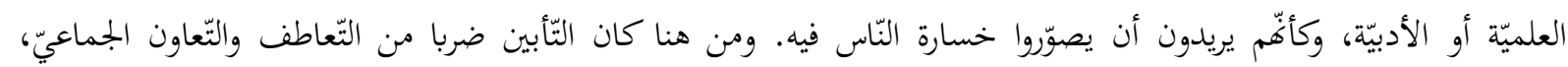

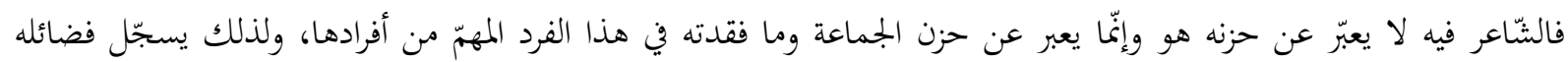
ويلحّ في هذا التّسجيل وكأنّه يريد أن يحفرها في ذاكرة التاريخ حفرا حتّى لا تنسى على عنى مرّ الزمان. إنّ شعراء لبنان المعاصرين أيضا في رثائهم لأهل البيت، ذكروا فضائلهم ومحاسنهم، وقد وصفوا هذه الفضائل في أشعارهم،

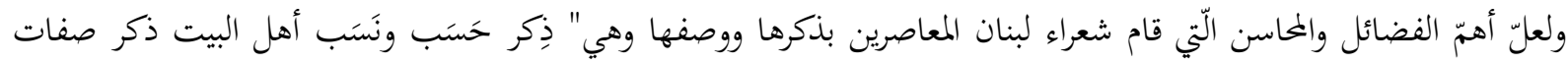

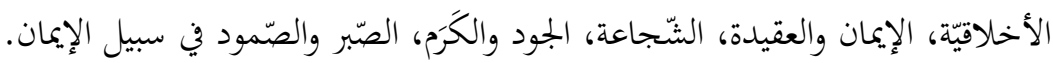
فالثّاعر بولس سلامة، يذكر عليّا في شعره بألقابٍ مختلفة منها: "سِدرة المنتهَى في الكمال الإنسائّ"، و"عليّ العصور" 
وهو يتكلّم عن عظمَة عليّ وفضائله ويعتقد أنّ الله خلق عليّا لمناصرة أفضل أنبيائه. وأنّ عليّا هو نور الهداية الذي يُهدى

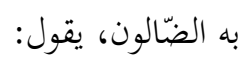

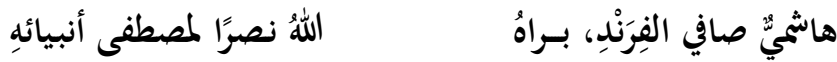

$$
\begin{aligned}
& \text { في خِضَّمّ من الضَّياءِ رحيبٍ }
\end{aligned}
$$

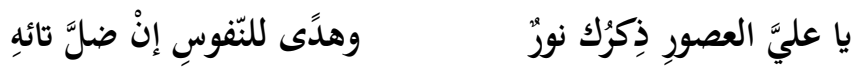

(عقل، 2009، 261)

والشّاعر المسيحيّ المعاصر جوزيف الهاشم الّذي يُعدُّ من أبرز شعراء النّصرانيّة في الأدب المعاصر، له ديوان شعر تحت

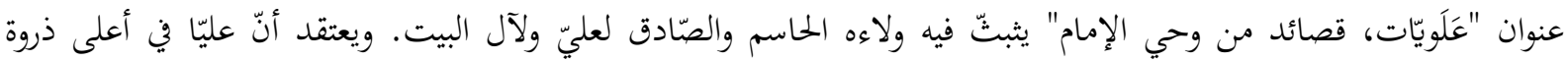

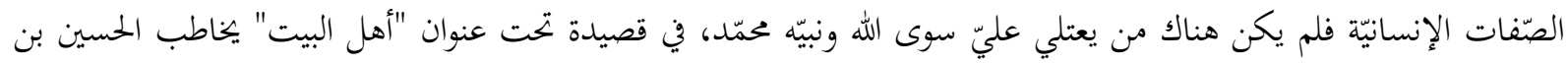
علي ويقول:

$$
\begin{aligned}
& \text { يا ابنَ العليّ، ومن يعلو العليّ سِوى اثنين، ربّك فوقَ الرّسلِ كِلّهم }
\end{aligned}
$$

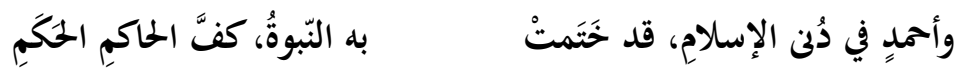

(الهاشم، 1999)

وفي موضع آخر يتكلّم الشّاعر عن نَسَب عليّ بن أبي طالب ويمدحه، ويذكر بعض صفاته كمولود في داخل الكعبة،

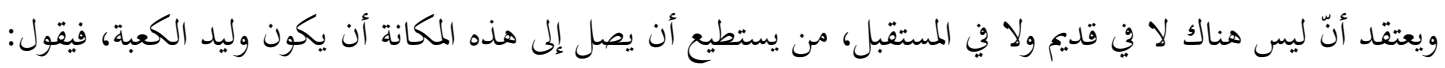

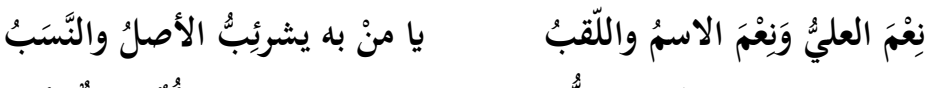

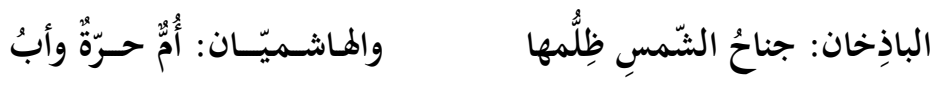

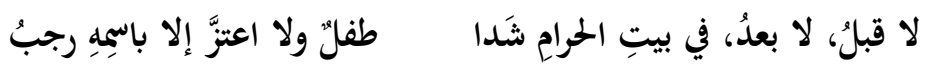

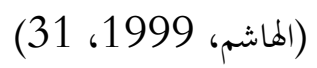

ويذكر الشّاعر أيضا صفة أخرى لعليّ، وهي أسبقيّة عليّ في الإيمان حيث سبق النّاس بالإيمان فكان أوّل من آمن بالله والرّسول في حين كان النّاس يعبدون الأوثان ويشركون بالله، فيقول:

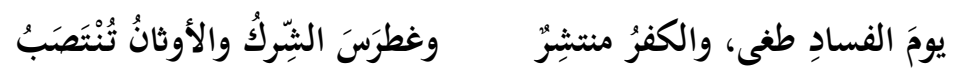

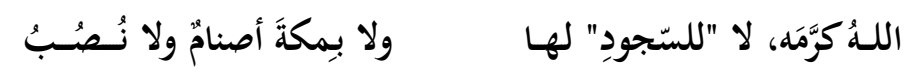

(الهاشم، 1999، 31). (الم،

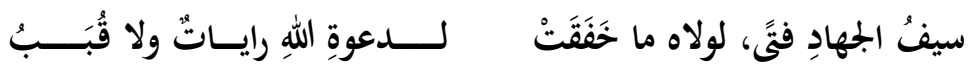

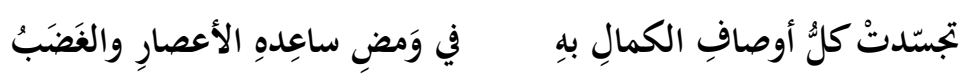

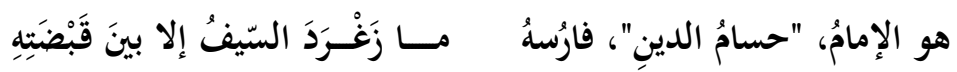

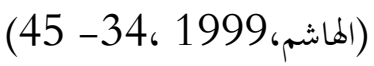

ومن الفضائل التّي يشير إليها الثّاعر حول عليّ، سِعة علمه، وفي هذا المجال يذكر عليّا بِلَقَبَيْن: "سيّد البيان" و "باب

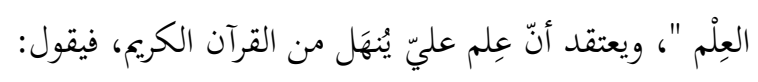

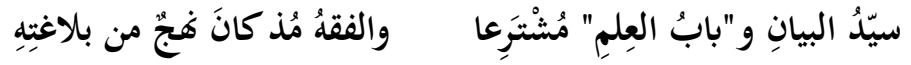

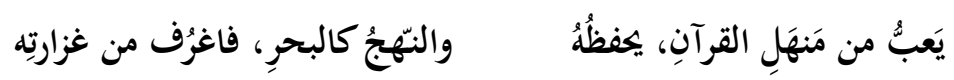




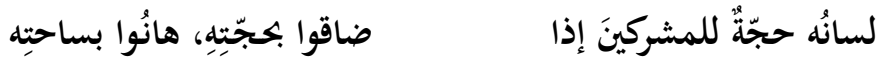

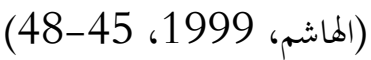

يصوّر الشّاعر في هذه الأبيات العلاقة الوثيقة فيما بين القرآن وكتاب "فج البلاغة" لعليّ، ويعتقد أنّ عليّا قد تلقّى معارف القرآن الكريم من صميم وجوده، واحتفظ بهذه المعارف في قلبه وعمل بها قولا وفعلا في حياته.

ومن الصَّفات الخلقيّة والفضائل التّي اعتنى بما الشّاعر المسيحيّ المعاصر في قصائده في رثاء علي بن أبي طالب وأمعن

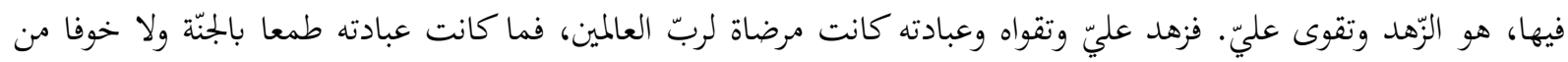

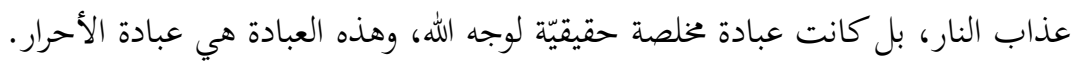

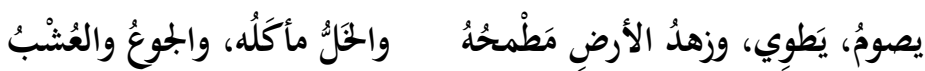

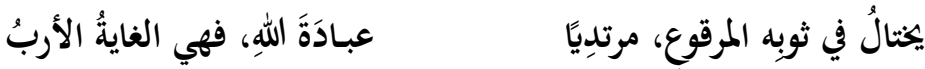

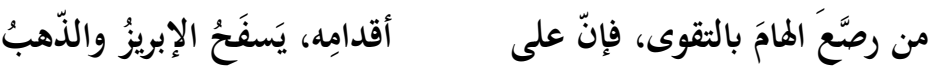

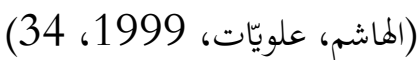

والشّاعر جوزيف الهاشم في قصيدة أخرى أنشدها في رثاء الحسين بن عليّ بهذا العنوان "مُشْعِل الثَّورَتَين"، يذكر فضائل

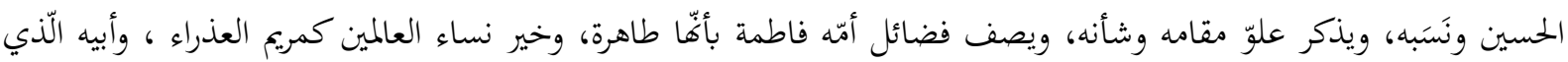

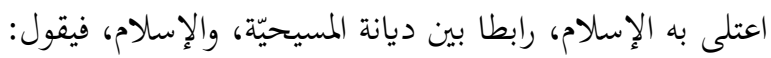

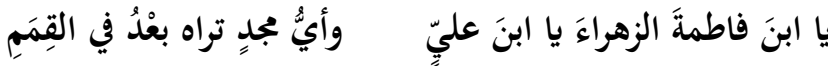

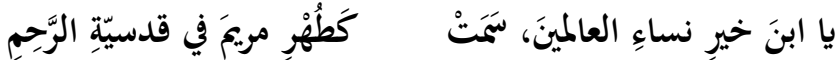

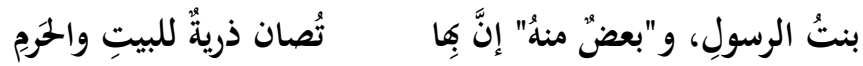

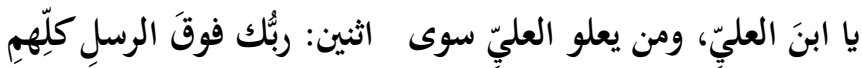

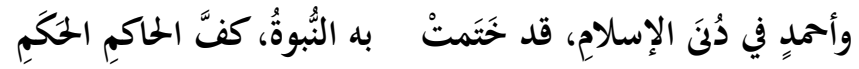

(الهاشم، 1999، 58)

وللشّاعر المسيحيّ المعاصر ريمون قَسّيس قصيدة طويلة في رثاء الحسين، بعنوان: "ملحمة الحسين" تقع في 114 بيتا، يوظّف الشّاعر في مطوّلته هذه أغراضا شعريّة مختلفة، كالمدح والصّور الأدبيّة المتنوّعة ويذكر مقاطع من ثورة الحسين، كما يذكر

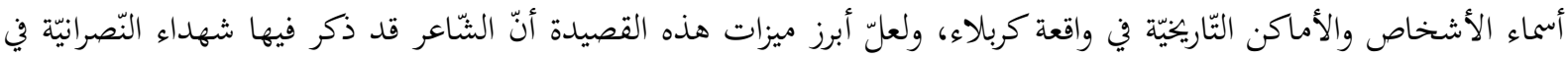

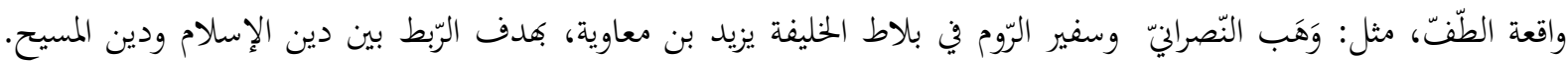

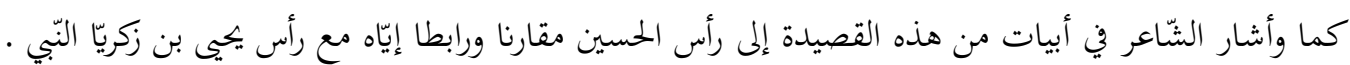
فيذكر الثّاعر في هذه القصيدة فضائل الحسين ويعتقد أنّه وجه رسوليّ، وهو سِبط النّبيّ الأعظم يحمل رسالته النّبويّة

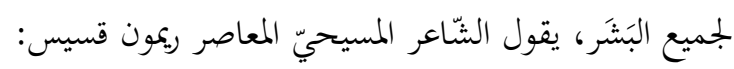

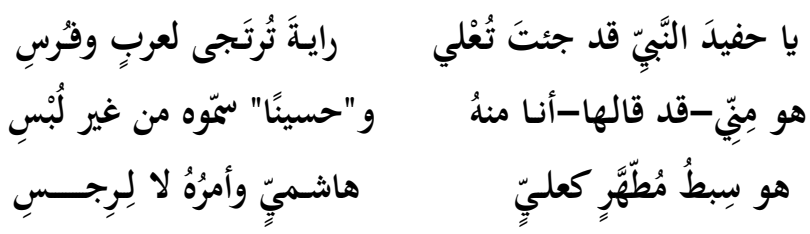

(قسّيس، 2011)

يشير الشّاعر في هذه الأبيات إلى الحديث النّبويّ القائل في حقّ الحسين: "حسين منّي وأنا من الحسين" الّّي يدلّ على

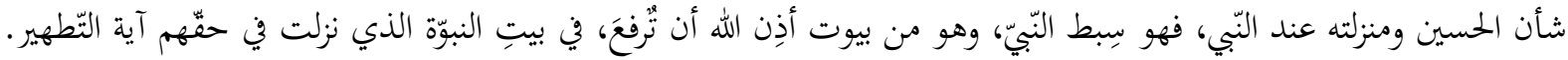


ويواصل الثّّاعر ريمون قسيس أشعاره بذكر فضائل الحسين في قصيدته "ملحمة الحسين"، فالحسين لا بديل له في

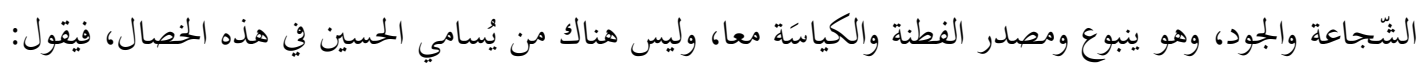

\section{جرأَة في شجاعةٍ جودُ كفِّ}

(قسيس، 2011، (29)

والحسين هو أبو الأئمّة الّذي يُهتدى به كما يُهتَدى بالفَرقَد بدون ذهاب ضوء، فيقول الشّاعر ريمون قسيس:

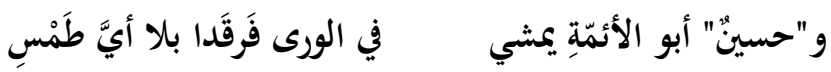

(ن) (ن) (ن)

قد شبّه الشّاعر في هذا البيت شأن الحسين بن عليّ في الهداية إلى نور النّجم الّنّي يضيء طريق الحقّ للبشريّة فيهتدي به البشر .

والشّاعر جوزيف الهاشم يصف الحسين بأنّه قد نَذَر نفسه الطّاهرة، وقد جاد بنفسه وهو غاية الجود ليكون شهيد الحقّ

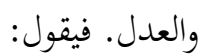

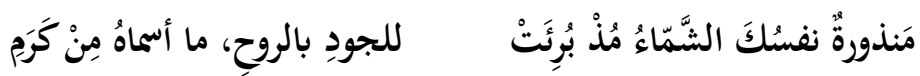

(الهاشم، 1999، (المر،

من القضايا التي اعتى هها الشّاعر أثناء رثائه لكبار الشّخصيّات، هو ذكر المصائب والمحن والآلام التي شهدها وواجهها

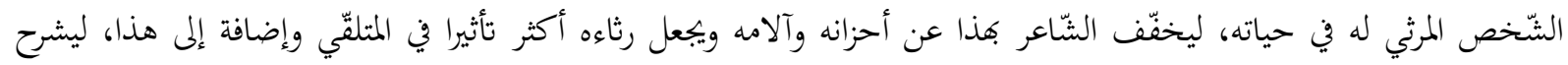
للمتلقّي مقاطع من واقع حياة المتوفّ في الماضي ليتعرّف عليه ويتأثّر من فقدانه.

فمن المصائب والمحن التي شهدها أهل البيت في حياتم وقد غيّرت هذه الحادثة مسار التّاريخ بأكمله هي قضيّة السَّقيفَة

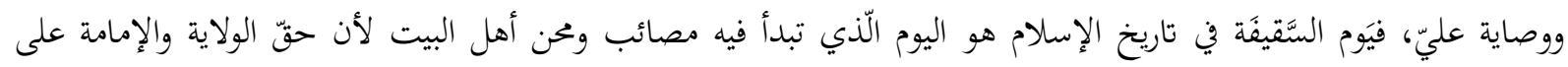
المسلمين قد اغتُصب من عليّ وأبنائه وقد كان أمرا إلهيّا.

وقد نزلت في هذا الشّأن آية تُعرف لدى الشّيعة بآية إكمال الدّين، قال الله تعالى: (اليوم أكملتُ لكم دينَكم وأتممتُ

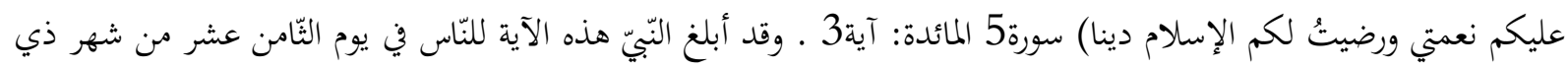

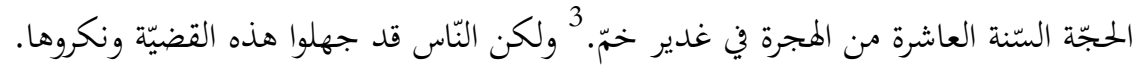

إنّ الثّاعر المسيحيّ اللّنبانيّ يرثي أهل البيت، ويشير إلى هذه القضيّة ويعتقد أنّه يوم السَّقيفَة هو اليوم الذي نُمكِّست فيه

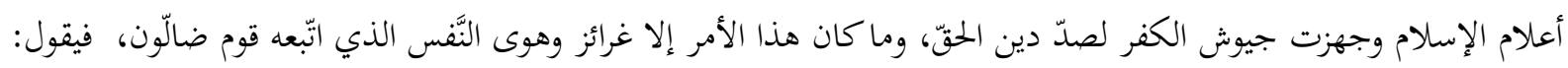

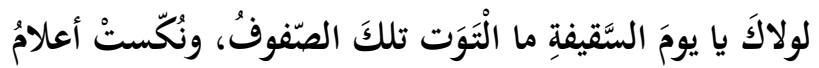

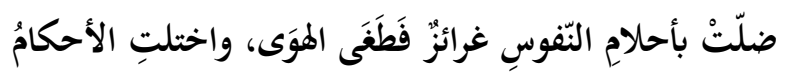

(الهاشم، 1999)

لا شكّ أنّ واقعة الطّّت هي من أفجع الأحداث في تاريخ الشّيعة، وقد وصفها الشّعراء في العصور المختلفة ورثى لمصائبها

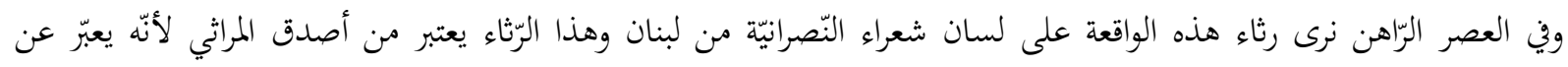
عاطفة صادقة رسمتها ريشة هؤلاء الشّعراء. 
فالثّاعر ريمون قسيّس يذكر زينب بنت عليّّ في مقاطع من قصيدته ملحمة الحسين بحماس ولففة، وبالاستعانة ببعض

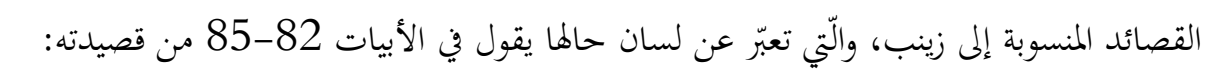

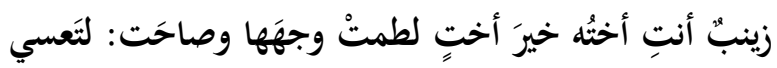

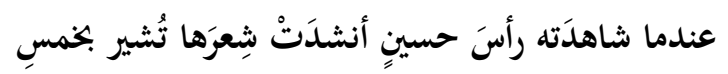

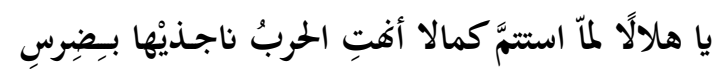

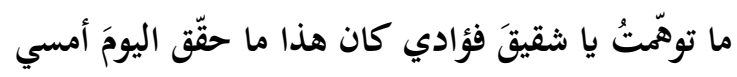

(قسيس، 2011، 37)

وأمّا الثّاعر اللبنانيّ المعاصر جوزيف الحرب، يرسم تلك المحن والمصائب التي حلّت بآل الرّسول، ويتفجّع لمشاهد منها.

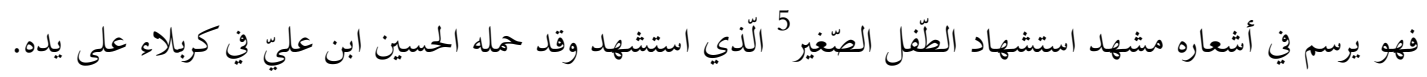
ويعتبر هذا المشهد من أفجع وأبشع مشاهد واقعة كربلاء والّذي لن ينمحي من ضمائر البشريّة، عندما طلب الحسين شربه

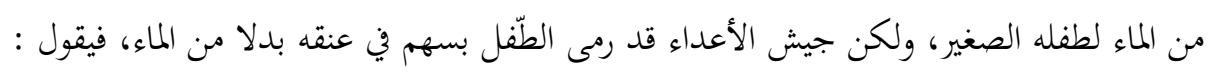

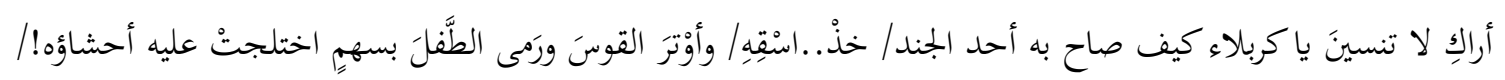

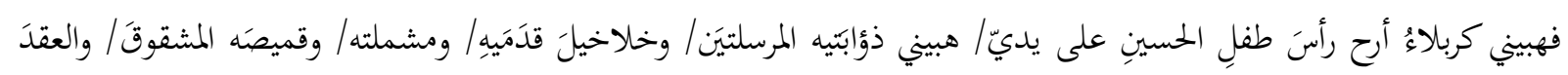

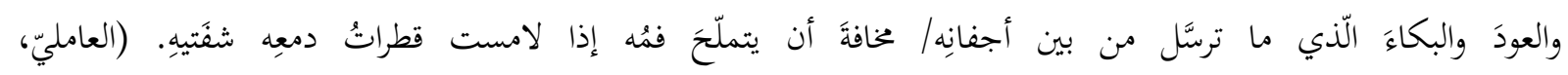

(42 2001/ 1422

\section{دور أهل البيت في إحياء دين الإسلام}

يعتقد الثّيعة أغّّم قدّموا حياقمم من أجل تثبيت الدّين والعقيدة، وقد جاهدوا في هذا السّبيل إلى درجة الاستشهاد

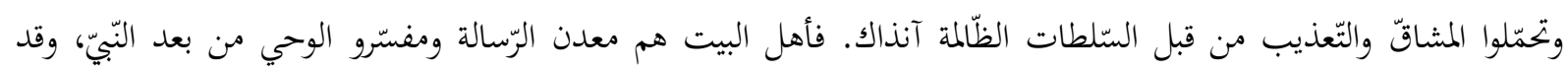

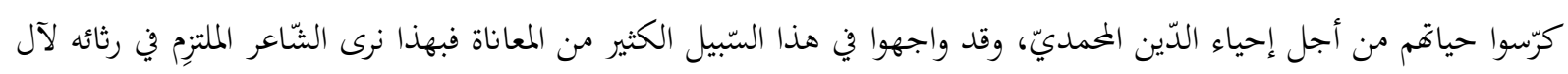
بيت الرّسول يشير إلى دورهم ومنهجهم وبجاهداقم في إحياء إحئ الدّين.

فنرى الشّاعر المسيحيّ المعاصر جوزيف الهاشم يتطرّق إلى دور أهل البيت في إحياء دين الإسلام، ويعتقد أنّه لولا علي لما

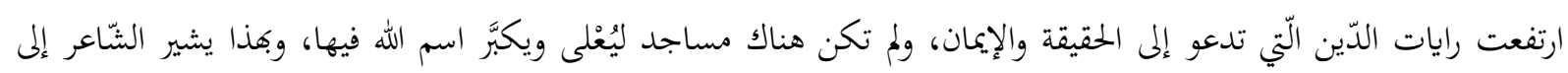

$$
\text { دور عليّ الحاسم في تعزيز الدّين، فيقول: }
$$

(الهاشم، 1999، (المب، (19)

وهذا ريمون قسّيس يقول: قد أراد الحسين من مقتله في معركة كربلاء الّذي كان قدرا مقدّرا من لدن الخالق، أن يترك

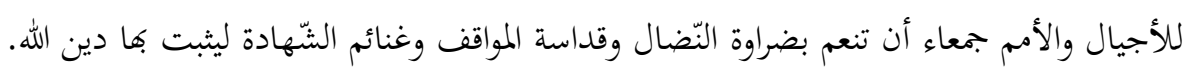

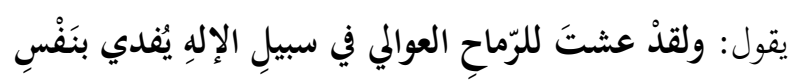

(قسيس، 2011، (ق24)

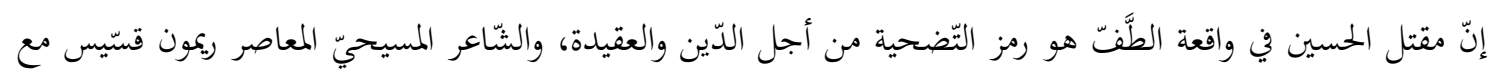
وصفه لمواقف واقعة عاشوراء ومقتل الحسين، يصوّر مدى دور الحسين في إحياء دين الله، فمقتله لم يكن إلا دعوة من الله وقد لبّاه

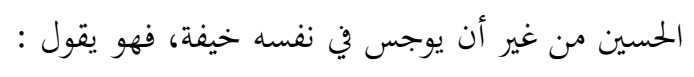




\section{(ن) (ن.)}

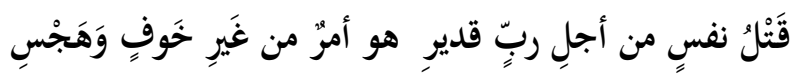

وفي هذا السّياق يصف جوزيف الهاشم مقتل الحسين بن علي في كربلاء بأنّه ثورة، وبرأيه أنّ هذه الثّورة قد حقّقها الحسين

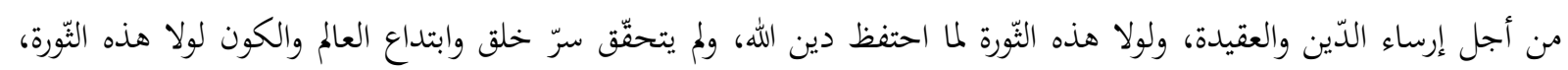

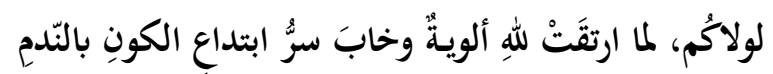

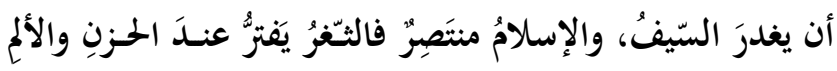

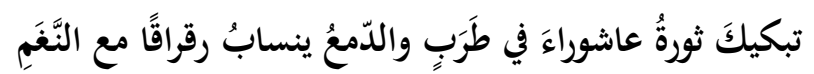

\section{(الهاشم، 1999، (الق)}

يشير الشّاعر في هذه الأبيات إلى انتصار الدّم على السّيوف، وهو انتصار حقيقيّ كما يعتقد أنّ شهداء كربلاء قد

$$
\text { انتصروا بدمائهم في غهاية المطاف على أعداء الإسلام. }
$$

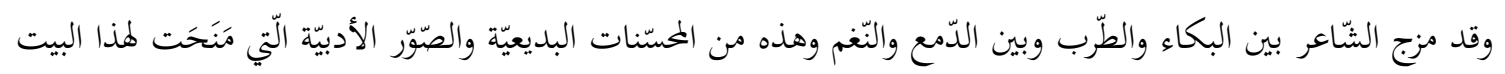

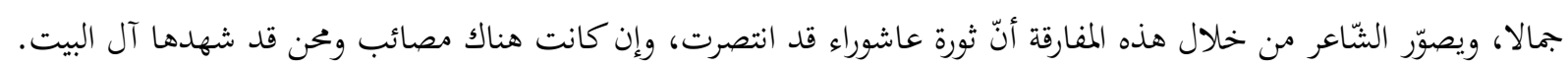

\section{النّيجة}

نستخلص من هذه الدّراسة الّتي تناولت رثاء أهل البيت في الشّعر شعراء لبنان النّصارى المعاصرين النّائج التّالية: - يرى شعراء النّصارى اللّنبانيّين أنّ أهل البيت هم أسوة الإيمان والعقيدة، وأنّ حبّهم هو حبّ الإيمان والكمال والحريّة والشّجاعة والعدالة والثّهادة والقيم الإنسانيّة السّامية، لذلك فليس عجيبا أن يشترك المسلمون وغير المسلمين في هذا الحبّ المعنويّ. - تأثر شعراء لبنان النّصارى المعاصرين من عظَمة أهل البيت، وقد نظموا الكثير من القصائد في رثائهم وقد تكلّموا فيها عن عظَمة أهل البيت. - اهتمّ الثّعراء في العصور المختلفة برثاء آل البيت، وفي العصر الرّاهن نرى أيضا قصائد كثيرة في رثاء أهل البيت عليهم، ونشاهد قصائد صادقة على لسان شعراء لبنان المسيّحين. - اهتمام شعراء لبنان المعاصرين بعقيدة صادقة في رثاء أهل البيت، وقد عبّوا في قصائدهم عن حزهم وآلامهم من مقتل أهل

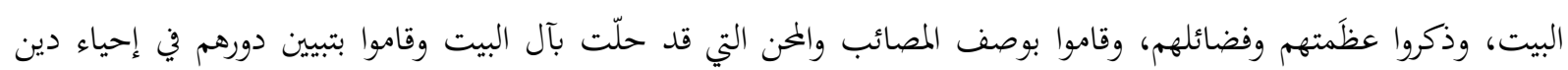
الإسلام. 


\section{قائمة المراجع والمصادر}

أخطب خوارزم، الموفّق بن أحمد المكّيّ. مقتل الحسين للخوارزمي. تحقيق: محمّد السّماويّ. قمّ: مطبعة أنوار الهدى،

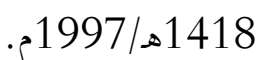

الأميني، محمّد هادي. عيد الغدير في عهد الفاطميّين. طهران: مؤسّسة الآفاق، 1417هـ/1997م. الأميني، عبد الحسين. الغدير في الكتاب والسّنة والأدب. قمّ: مؤسّسة دائرة الفقه الإسلامي، ابن فارس، أحمد. معجم مقاييس اللغة. تحقيق: عبد السلام هارون، بيروت: دار الفكر للطباعة والنشر، 1979.

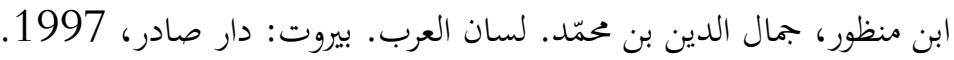
أصغر ياري، علي، رضائي، عليّ محمّد. الإنزياح والتكرار في ملحمة الحسين لريمون قسيس: دراسة أسلوبيّة ، دراسات استشراقيّة،

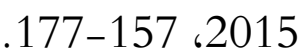

الجُمَحي، محمّد بن سلّام. طبقات فحول الشّعراء. شرح محمود شاكر، القاهرة: مطبعة المدنيّ، 1974. الجوهري، إسماعيل بن حمّاد. تاج اللّغة وصحاح العربيّة. تحقيق: أحمد عبد الغفور عطّار، بيروت: دار العلم للملايين، 1990. الخطيب، بشرى محمد علي. الرّثاء في الشّعر الجاهليّ وصدر الإسلام. بغداد: مديريّة مطبعة الإدارة المحليّة، 1977.

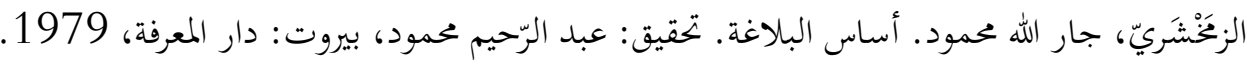

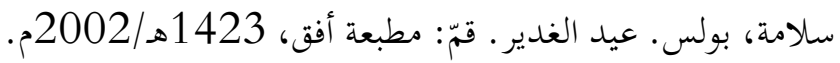

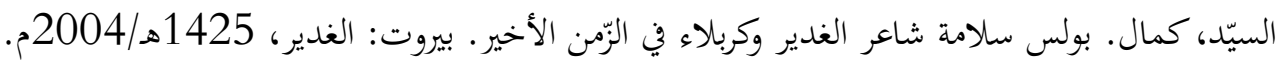

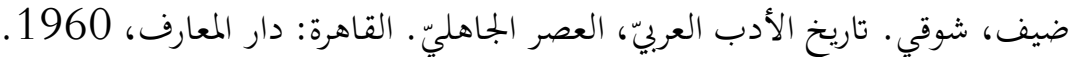
ضيف، شوقي. فنون الأدب العربيّ، الرّثاء.ط.4، القاهرة: دار المعارف، 1988.

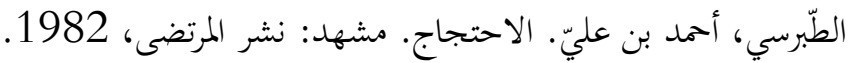
الطّوسي، أبو جعفر محمّد بن الحسن. الأمالي. تحقيق قسم الدّراسات الإسلاميّة مؤسّسة البعثة. قم: دار الثّافة للنّشر، 1414/1993

العامليّ. الانتصار مناظرات الثّيعة في شبكات الإنترنتّ المجلّد التّاسع دفاعا عن مراسم عاشوراء وقداسة كربلاء والتّربة الحسينيّة. بيروت: دار المسيرة، 1422هـ/ 2001م.

عبّود، مارون. أدب العرب. بيروت: دار الثّقافة، 1960.

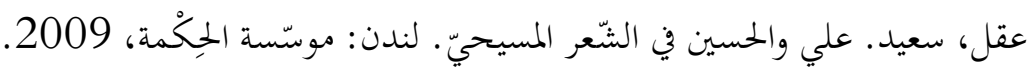

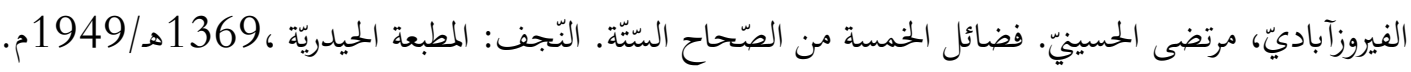

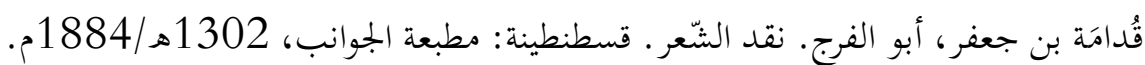

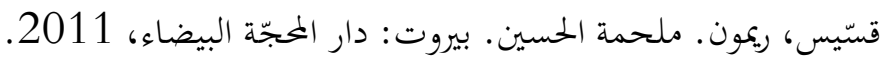

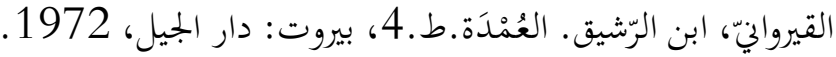
الكِرباسي، محمّد صادق. شريعة العيد. بيروت: بيت العلم للنّاهين، 2009.

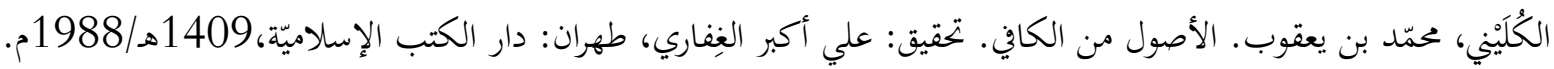

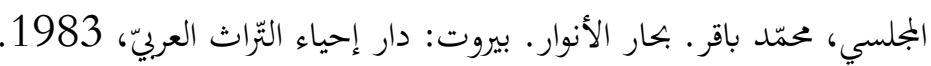
مُحََّدِثي، جواد. موسوعة عاشوراء. ترحمه من الفارسيّة إلى العربيّة خليل زامل العِصامي، بيروت: دار الرّسول الأكرم، ودار المحجّة

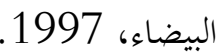

المرتضى، الشّريف عليّ بن الحسين. الشّافي في الإمامة. طهران: مؤسّسة الصّادق، 1987. 


$$
\begin{aligned}
& \text { النّعمة، مقبول علي بشير . المراثي الشّعريّة في صدر الإسلام. بيروت: دار صادر، } 1997 .
\end{aligned}
$$

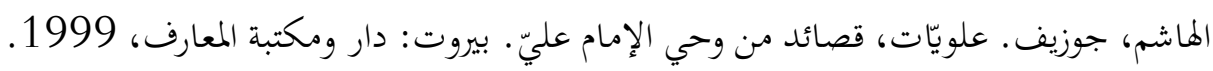

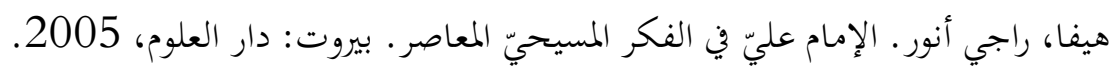

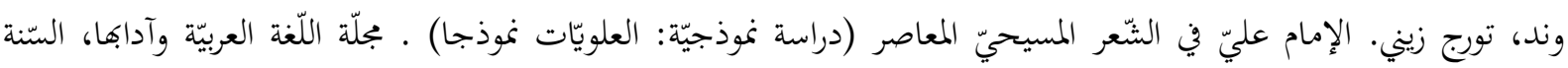

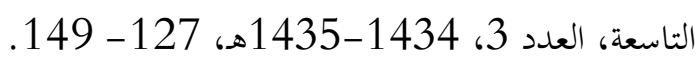

Bar-Asher, Meir. Scripture and Exegesis in early Imami Shiism .(Leiden: Brill, 1999).

Beinhauer-Köhler, Bärbel. Fatima bint Muhammad: Metamorphosen einer frühislamischen Frauengestalt, (Wiesbaden: Harrassowitz Velgar, 2002), 129-131.

Massignon, Louis. Der gnostische Kultus der Fatima im schiitischen Islam, in: Eranos Jahrbücher, (1938), S. 162.

McAuliff. Jane Dammen, Chosen of All Women: Mary and Fatimah in Qur'anic Exegesis Islamochristiana 7, (1981), 19-28.

Pinault, David. Zaynab bint 'Ali and the Place of the Women of the Households of the first Imams in Shi'ite Devotional Literature, in Women in the Medieval Islamic World, edited by Gavin Hambly, New York: St. Martin's Press, 1998, 69-98.

Sindawi, K., (2004). Al-Husain Ibn 'Ali and Yahya Ibn Zakariyya in the Shi'ite Sources: A Comparative Study. Islamic Culture.78(3), 37-54.

Veccia Vaglieri, L. Ghadir Khumm, Encyclopaedia of Islam, new edition, II, p. 993-994.

Sered, Susan. Rachel, Mary, and Fatima, Cultural Anthropology 6 (1991)، 131-146. 


\section{الهوامش}

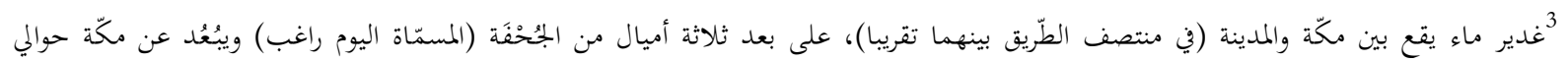

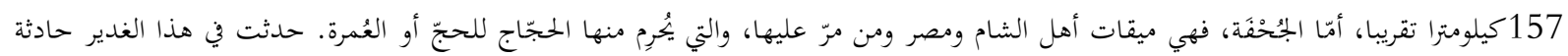

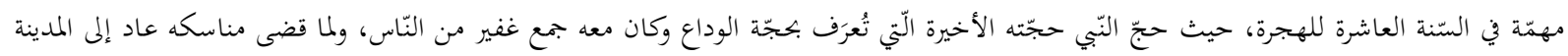

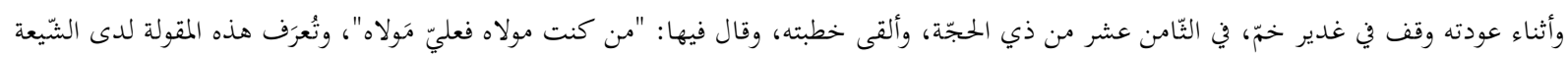

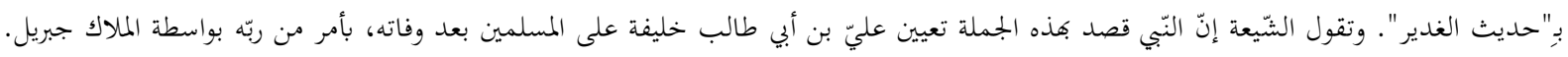

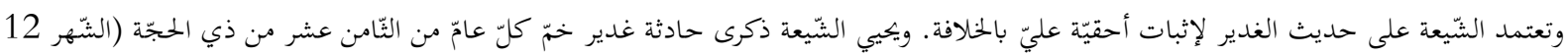

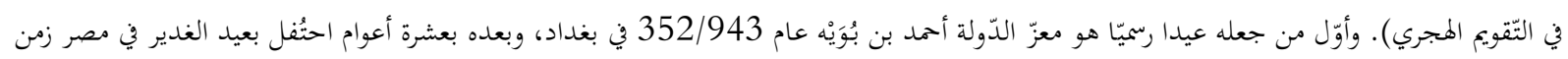

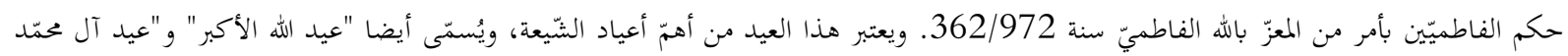

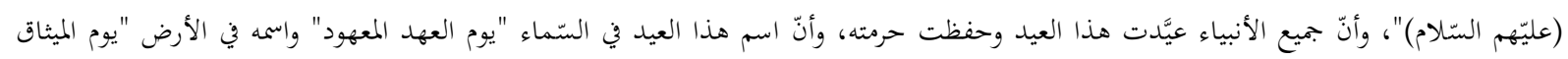

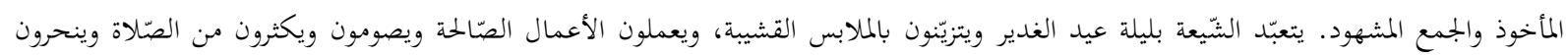

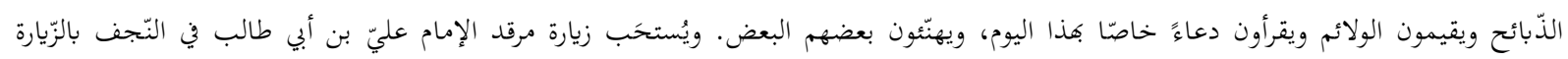

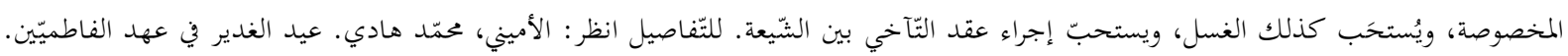

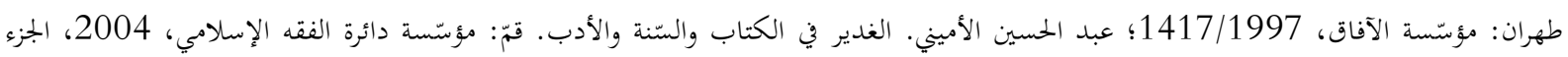

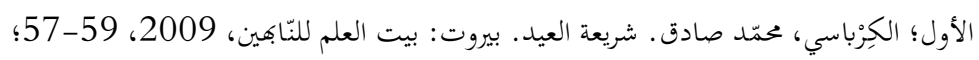
Veccia Vaglieri, L. "Ghadir Khumm", Encyclopaedia of Islam, NeW edition, II, P. 993-

994.

4هي زينب بنت علي بن أبي طالب، أمّها فاطمة الزّهراء.وبكسب بعض الروايات إنّ النّبيّ سمّاها زينب .شاركت أخاها الحسين في واقعة الطّّنّ، وكان لها

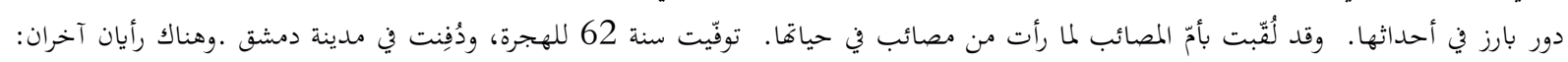

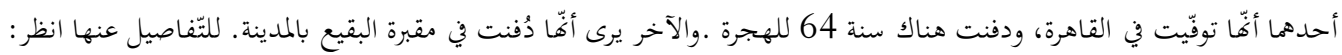

Pinault, David. "Zaynab Bint 'Ali And the Place of the Women of the Households OF the first Imams in Shi'Ite Devotional Literature," in WOMEN IN THE Medieval

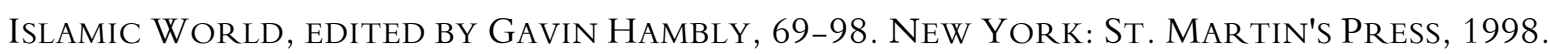

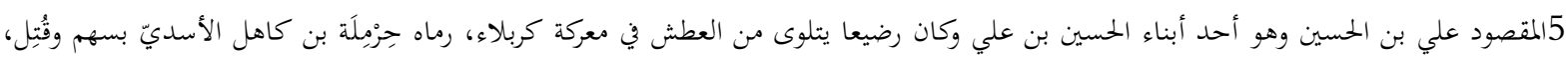

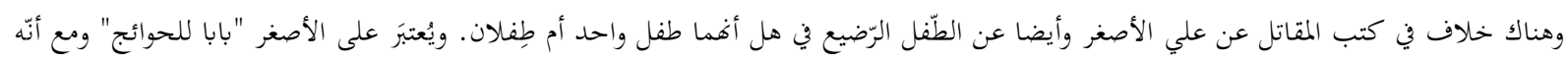

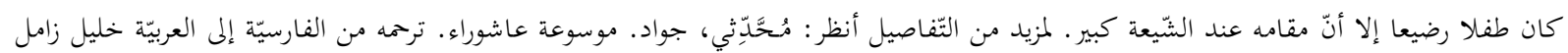

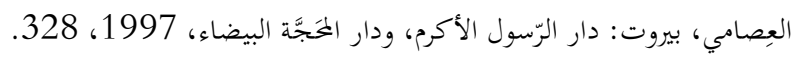

